\title{
號九十七第告報會究研事醫堂天順 $\mathrm{O二三}$
}

干

八

百

八 (9)

+ 肺

六炎

年 $=$

力 於

ぜケ

i 2

I 刺

十 絡

莡 法

는

u

1)

1

$\frac{1}{2}$

นิ

䇂

$\infty$

$\rightarrow$

$\stackrel{10}{3}$

.

$\frac{\sqrt{3}}{0}$

於

$\%$

起
苞者泀电段) 此

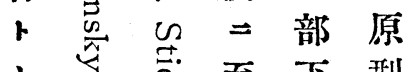

+灾至下型

心

?

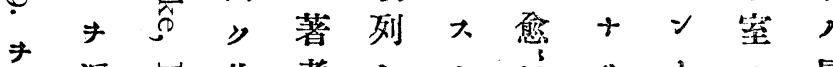

比避此者をル長り", 最

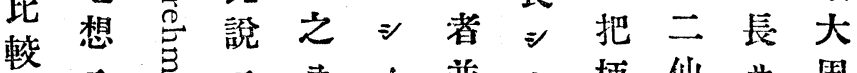

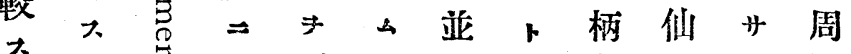

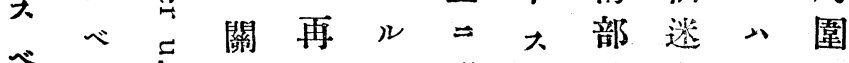

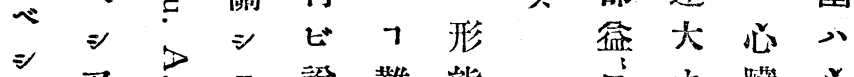

、圣 $>$ 說難 態長ナ臟心

カカ ガ カカ

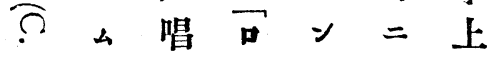

$\div$ ○ 七 77 相

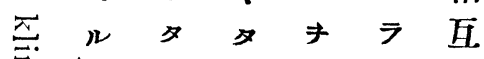

压ルン粎犬゙連

壳 小 $、$ 而繫

巳

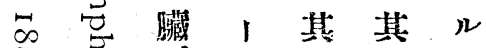

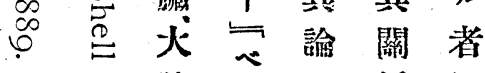

乙, 肺子夫係固

10 踹、結八

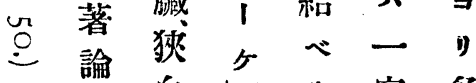

管 学定, 多

等 2 抄病

, 1 録的

肺义者素心

学等等爷因

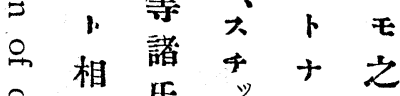

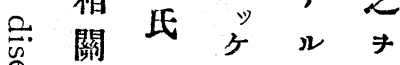

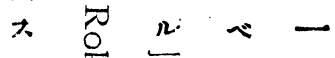

京式 $\neq$ 定
》》基 藏

助胸底底

間骨, ,

愈体周 周

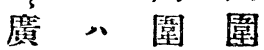

与其 $\Rightarrow=$

レ把超均

s 唡 $=$ =

大部 ル

動 = 殆

尿 斨

, $=1$

內 $\overline{-}$ -

積 大 仙

谷十迷

少口 =

$+=y$

》嘥

上七左

行心等

胸哌,

部 八長

大愈 サ 


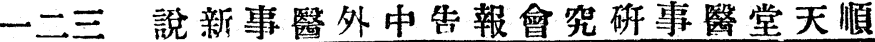

(0) 人歲千 氏

䍨死乃八,

类者 至百 綐

$=$ 一四入言

於人十+ $1+n$ 减

十歲六據作兵シ减

几り九年レ用肺テ大

刺翌人全八ま充其二

絡 七四患

法年十者

$\Rightarrow$ 嵗 數

$\therefore$ 万 二

二至十

十五五

枀十此

人 歳内

中四三

$=1+$

十五 歲

營 血 性 三

厶及質 露

モ七

敢副艮痛

テ發 $+*$

心浮 $ラ$ 輕

力 腫 $三$ 减

葴 十 以

以甬下

下至一

三六人

$\Lambda+=$

二歲十

+ - 歲

万人加

至 $=$ 至

$\equiv=\equiv$

$=+\bar{\tau}+$

歲 治 歲

四者十

$\Lambda=\Lambda$

三丨

+ 四 +

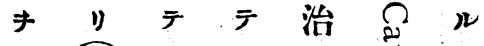

但霄未方总脯

$\Rightarrow=\Rightarrow$ * 笑

初當衰求川山

メ時弱 メ當 其

八㯪七刀時性

瀉之乩り從重

血

量應若氏, 上

一用 ₹ 八療死

八 女者初法者

$0=\neq x$ 總,

瓦, 撰 其テ多

以 : ミ 第 無 キ

上十 其 一 效

$=$ 充試 $+=$

至犬゙血驗り由

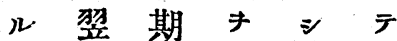

$\neg$ 二 = 篇 $=$ 著

十年當入问

力間 $\bar{C}$ 十

リモ刺當不リ

₹亦絡》得 $\approx$

氏之 純止涩

$\therefore$ ๖粹 き グ

刺肺几格二小

絡炎 = 魯彼

収 ショ

₹ $=$ 且

促 么

万、淬

五 出

八呼 物

以 吸中

上困,

二患其布古カ

由 者効性 法

》 $\Rightarrow$ 肺 $\Rightarrow 1$

左行思炎ル

， 工案患刺瓦

効 = 外者 絡 口

$\boldsymbol{P}$ 至 $=\Rightarrow \Rightarrow$.

$\nu=\geqslant$ 其 


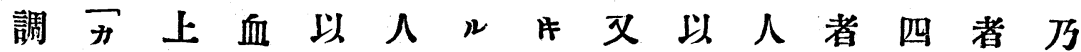
查每, 期上充者八千上三三十二至 二八者十, 血九充八一十+十歲人四 係自三儿者期人血百人乃七十 ル個人人一三三期入 死, 十化人十百二十 亡患”肝十人瓦十六テ十者四入人 數 者き期》化以三年治歲二十年四 ま中十翌肝上人一者三人乃 示刺人八期, 化回總十十至八乃 二絡湢年六者肝刺數四》五二至 厂 $\neq$ 血 $=$ 人一期絡七人故十十五 之施量八殆人三未十四 $三$ 藏九十 * \#殆一ト+人行五十總二人歲 比・回二”瀉七人歲計人中六 較”二刺百翌血》死乃八五二人 七 百絡至七, 几者至十十+五 》以瓦, 十年量者總五八刀歲十 即前, 者

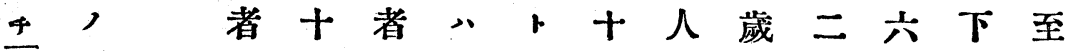
天死十九十一五即十+十三共 二 ᄃ 三人入回百八士三歲歲人十

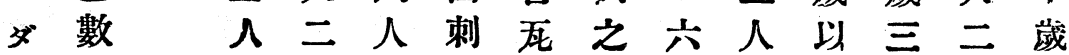
式 舉百, 上七几病四十六六乃人 会无者三三者, 分乃人十至二 犬, 九百者十時, 至三歲三三 八其者人瓦三五期一六十以十 一 代

$\equiv$ $t=$ $\%$ 他 ブ 諸 $+三,+人=\%+$ 万嵅治 四回者人殆從 + 歲至一六者 人, 七三十 三者八回三區 $\neq 人+=三+$ 百一三，百別宍藏 $三 十$ 四

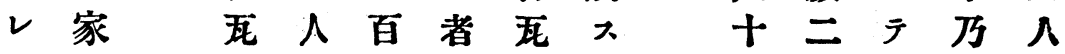
， 以充瓦六 $+n$ 歲十治至死 
三二三說新事醫外中告報會究研事醫堂天順

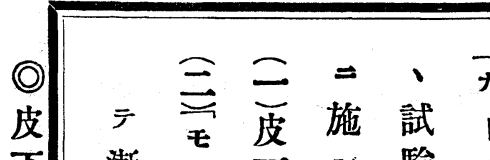

下漸此

泩 $\nabla$ 七 $=$ 左 $G n$ ( )

入》予泩, 草卜皮

正弱

モり皮七績导

凡.五下

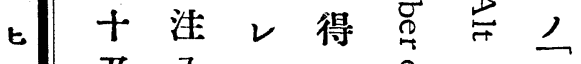

于

傗

$\exists$

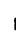

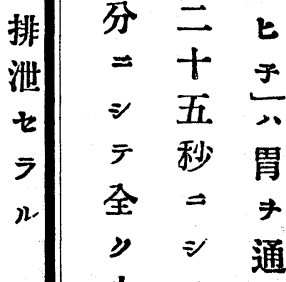

止 $テ \%$

ム証 テ

明 排

七 池

₹

ル

ヘ $ル$

$\eta$

其

持

$+$

五
$?$ ㄷ

皮皮

苞下

: $=$ 于

泩 胃

号不

? り

冯

こ $v$ 泄

$\stackrel{\rightleftarrows}{\rightleftarrows}$ 七

苛 少

モ

$\underset{7}{\square}$

当

莺 手

胃

2

号 通

$\stackrel{2}{3}=$

总 泄

○

$* \Rightarrow$

犬 $n$
公排
續

半

特

$$
\Rightarrow
$$

\#
ノキ十氏 適者り八實 1 度卜・現驗怘 八ナ+今 二 七 $三$ 傳 ○リ刺染所受四 $\bigcirc$ 而絡病 $=$ 車 0 万メ 至刺原 $=$ 七七 三絡因從 蛙山 ○, 療 七 入 \% 到 ○禁法刺十名江 互导卜絡名 $\overline{1}$ , 症。厂中 間 八 底五モ心 二老徵效名 学 ア衰候きノテル导 全的以死芪学

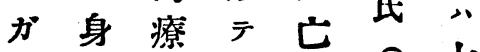
如貧法身 $\boldsymbol{P}$ 七 少, 体》兽

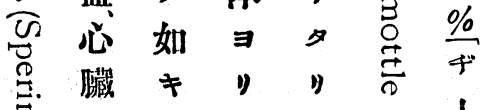
等 导脂肺 急 即-

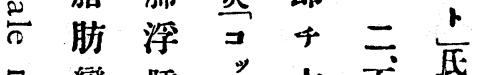

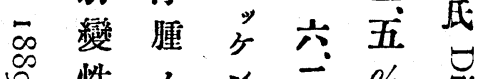
○ 性, $=$ 三 等初吾十 吾

五 + 期 排 \% 》 ” $v=$ 泄 $十$ 而七 1. 適 $大, y$, 四

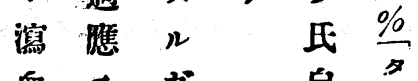
血大カ 量へ第 自 \# 